\title{
Efficacy of Chinese auriculotherapy for stress in nursing staff: a randomized clinical trial
}

\author{
Leonice Fumiko Sato Kurebayashi ${ }^{1}$ \\ Maria Júlia Paes da Silva²
}

\begin{abstract}
Objective: this randomized single blind clinical study aimed to evaluate the efficacy of auriculotherapy with and without a protocol for reducing stress levels among nursing staff. Method: a total of 175 nursing professionals with medium and high scores according to Vasconcelos' Stress Symptoms List were divided into 3 groups: Control (58), Group with protocol (58), Group with no protocol (59). They were assessed at the baseline, after 12 sessions, and at the follow-up (30 days). Results: in the analysis of variance, statistically significant differences between the Control and Intervention groups were found in the two evaluations $(p<0.05)$ with greater size of effect indices (Cohen) for the No protocol group. The Yang Liver 1 and 2, Kidney, Brain Stem and Shen Men were the points most used. Conclusion: individualized auriculotherapy, with no protocol, could expand the scope of the technique for stress reduction compared with auriculotherapy with a protocol. NCT: 01420835
\end{abstract}

Descriptors: Nursing, Team; Auriculotherapy; Burnout Professional; Clinical Protocols.

\footnotetext{
${ }^{1}$ Doctoral student, Escola de Enfermagem, Universidade de São Paulo, São Paulo, SP, Brazil.

${ }^{2}$ PhD, Full Professor, Escola de Enfermagem, Universidade de São Paulo, São Paulo, SP, Brazil.
}

Corresponding Author:

Maria Júlia Paes da Silva

Universidade de São Paulo. Escola de Enfermagem

Av. Dr. Enéas de Carvalho Aguiar, 409

Bairro: Cerqueira César

CEP: 05409-000, São Paulo, SP, Brasil

E-mail: juliaps@usp.br
Copyright $\odot 2014$ Revista Latino-Americana de Enfermagem This is an Open Access article distributed under the terms of the Creative Commons Attribution Non-Commercial License (CC BY-NC).

This license lets others distribute, remix, tweak, and build upon your work non-commercially, and although their new works must also acknowledge you and be non-commercial, they don't have to license their derivative works on the same terms. 


\section{Introduction}

In the health field, studies have been conducted on stress in nursing staff seeking to identify the main sources of stress in the nurses' practice in the different hospital areas, assessing whether the professional work performed in the sectors influences stress and anxiety levels. Nationally there is a consensus that this profession is stressful and research is mostly concentrated on the professional nurse ${ }^{(1)}$.

In the hospital context, the nursing staff constitute the largest work force and the activities carried out by its professionals are characterized by several negative determinant factors, among them, the fragmented division of tasks, the rigid hierarchical structure for the implementation of routines, rules and regulations, and insufficient qualitative and quantitative human resources, which result in high indices of absenteeism and sick leave(2). In fact, nursing staff are exposed to unhealthy work environments and often subjected to poor working conditions, leading to a low quality of life ${ }^{(3)}$.

From this perspective, there is a need to investigate the importance of developing coping strategies, from the participation of the professional in the work process, fostering motivation and providing better quality of life ${ }^{(4)}$. The importance is also emphasized of the prevention of health problems, with measures to help cope with the many challenges that are often outside the control of the workers yet impact excessively in their psychological and physiological conditions. To obtain a more balanced and stable energy condition, which is needed so that diseases do not manifest, auriculotherapy can be an unconventional practice of high acceptability, safety and efficacy, due to the recognition of its positive effects on physical, psychic and mental disorders ${ }^{(5)}$.

Over the last decade some studies have been conducted to evaluate the efficacy of auriculotherapy to reduce stress and anxiety ${ }^{(6-10)}$ and the preliminary trial that provided the basis for this research was entitled "Applicability of auriculotherapy with needles or seeds to decrease stress in nursing professionals", held in 2010, with nursing staff at the University Hospital (UH) of São Paulo. In the present trial, one of the intervention groups was based on previously tested points and the other intervention group was characterized by the choice of these points individually, similar to the usual clinical practice in Chinese medicine ${ }^{(11)}$. This study design emerged from a question regarding the difficult adequation of the Western scientific research approach in the analysis of the results of a medical rationality distinct from the West, originating from the Eastern Chinese culture. It is known that the protocol constitutes an important step in the performance of scientific research and is fundamental in the analysis of the efficacy of a given technique, medication or procedure. However, the transfer of the Western research concept does not always seem to be in line with the principles that underlie the alternative and complementary therapies ${ }^{(12)}$. In 1997, an important reflection on the "Westernization" of Traditional Chinese Medicine (TCM) was introduced, originating from a tendency to reduce the art of acupuncture to rigid formulas. Research work may prove, in part, the efficacy of the points, however, there is the opinion that this work does not represent true acupuncture, due to neglecting the holistic perspective of this practice ${ }^{(13)}$. In view of the previous statements, this study sought to evaluate whether the results achieved with individualized auriculotherapy are able to expand the scope of the technique, since the previous protocol results were positive for stress reduction in the nursing staff of the UH.

Regarding the ethical and legal aspects related to the practice of acupuncture by the nurse, it is noteworthy that this practice obtained legal support through Resolution 197/97 of the Federal Council of Nursing (COFEN) for the practice of acupuncture and auriculotherapy. Currently Resolution 326/2008, which replaced other previously issued resolutions (No.283/2002 and No. 287/2003), regulates the activity and provides for the registration of the specialty, giving support and legitimacy to the practice of acupuncture by nurses ${ }^{(14)}$.

\section{Aims}

The aims of this study were to evaluate the efficacy of auriculotherapy, with and without a protocol, in reducing the stress levels of nursing professionals; to evaluate the responses to the treatment according to the prior presence or absence of morbidity and different stress levels; and to evaluate the effect size of the treatments through the Cohen's d Index.

\section{Method}

This is a single-blind, Controlled Randomized Clinical Trial, with 3 groups: Control group (no intervention) Protocol group and No protocol group. It was approved by the Research Ethics Committee (CEP) of the University of São Paulo, under protocol number 1042/2011 and by the CEP of a private hospital. The study also fulfilled 
the requirements of Resolution 196/1996 of the National Health Council, regarding research involving humans, with the Terms of Free Prior Informed Consent having been delivered to the study subjects. The trial obtained the Clinical Trials registration number (NCT01420835).

Vasconcelos' Stress Symptoms List (SSL) ${ }^{(15)}$ was used to define the sample of subjects participating. The instrument was administered to all those who expressed an interest in participating in the study (484), however, only those individuals who achieved scores between 37 and 119 points were invited to participate; using numbers randomly generated by the site www. randomizer.org 213 people were allocated into three groups; 175 professionals were able to complete the study. There were 58 subjects in the Control group, 58 in the Auriculotherapy with protocol group and 59 in the Auriculotherapy with no protocol group. The sample calculation was performed using as a base the previous study of stress, and it was affirmed that the sample had a test power of $80 \%$ for a significance level of $5 \%$, or confidence level of $95 \%$.

The inclusion criteria were: voluntary participation in the study with the availability of time to attend the sessions, and obtaining a score in the SSL indicating a medium or high level of stress. The exclusion criteria were: nephrolithiasis with surgical indication (the Kidney point can stimulate the expulsion of stones), performing another energy therapy, taking anxiolytic or anti-depressant medication, or being pregnant. After the exclusions were made, a sample of 213 nursing professionals was obtained, conforming to the flow diagram of the subjects' participation. After the study began, 38 people were excluded for the reasons that are illustrated in Figure 1.

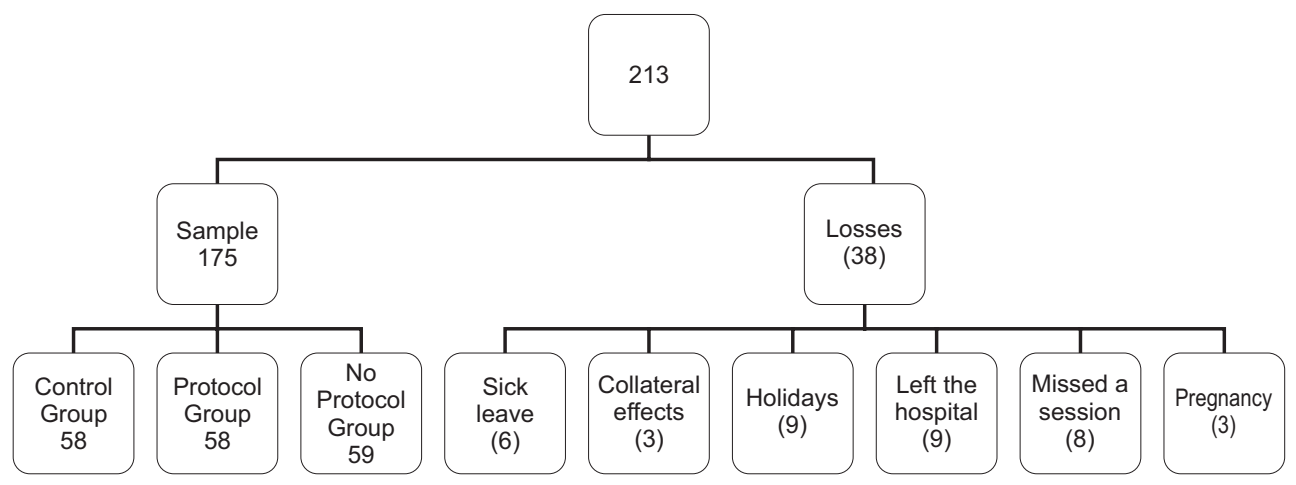

Figure 1 - Flow diagram of the study subjects. São Paulo, SP, Brazil 2012

The Data Collection instruments used were: Vasconcelos' Stress Symptoms List (SSL) and a questionnaire covering sociodemographic data and the presence of prior comorbidities. The data collection was carried out between January and July 2012, in the hospital, and the sessions were conducted by a group consisting of six acupuncturists nurses and a acupuncturist psychologist, trained in the same school, experienced in the use of the same technique of Chinese auriculotherapy. The SSL instrument was administered before the start (baseline), after 12 sessions, and at 30 days after the end (follow-up). The Control group received no type of intervention and was asked to only answer the questionnaires. The two intervention groups received 12 sessions (twice a week), with each session lasting 5 to 10 minutes. In the Protocol group the Shen Men, Brainstem, Kidney, Liver, Liver Yang 1 and 2 points (Figure 2) were used. The Shen Men and Brainstem points have calming properties, the Kidney point has an energy function, and the Liver Yang 1 and 2 points have the function of containing the rise of Liver yang(16).

The Group with no protocol also received the same number of sessions and points (5), however, the points were chosen dependent on the reported symptoms at each consultation, according to the Traditional Chinese Medicine diagnoses found. For placement of the semi-permanent needles, after the localization of the reactive points, cleaning of the pinna was performed, using cotton and $70 \%$ ethyl alcohol, and the needles applied and affixed with hypoallergenic tape. 


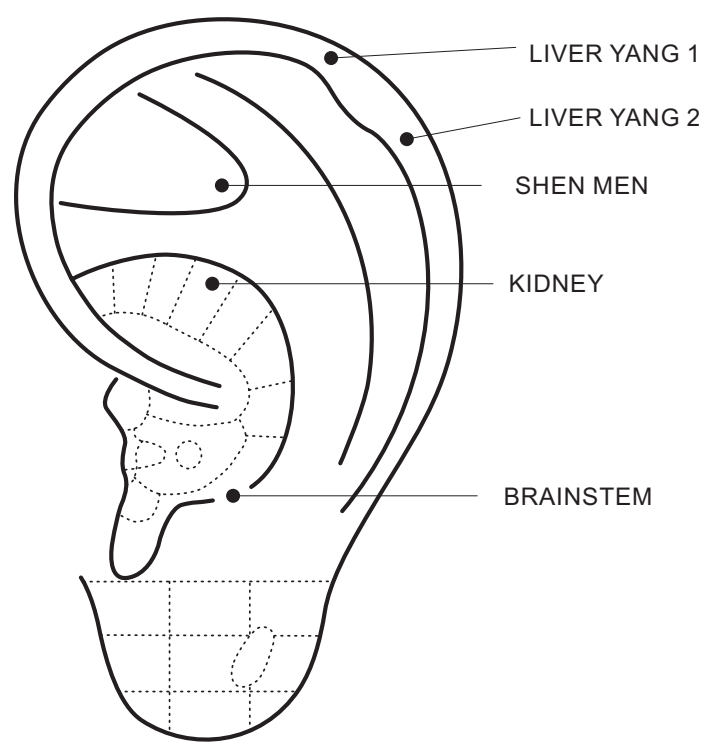

Figure 2 - Auricular points of the Protocol group. São Paulo, SP, Brazil 2012

\section{Results}

The mean age of the group of 175 individuals was 33.98 years $(S D=7.85)$, with a minimum age of 21 years and maximum of 58 years. The mean stress at the baseline was 61.48 (20.53), corresponding to a high stress level. The Cronbach's alpha for the SSL1 (baseline) was 0.918; for the SSL2 it was 0.947 ; and 0.955 for the SSL3. The following table describes the mean and standard deviation of the stress levels, according to the three different groups (Table 1).

Table 1 - Description of the means and standard deviation of the stress levels according to the 3 groups. São Paulo, SP, Brazil 2012

\begin{tabular}{|c|c|c|c|c|c|c|}
\hline & Groups & $\mathbf{N}$ & Mean & DP & 95\% Cl Lim.inf. & 95\% CI Lim.sup. \\
\hline \multirow[t]{3}{*}{ SSL1 } & 1 & 58 & 57.76 & 17.64 & 53.12 & 62.40 \\
\hline & 2 & 58 & 62.26 & 21.50 & 56.61 & 67.91 \\
\hline & 3 & 59 & 65.00 & 22.62 & 59.11 & 70.89 \\
\hline \multirow[t]{3}{*}{ SSL2 } & 1 & 58 & 65.38 & 22.49 & 59.47 & 71.29 \\
\hline & 2 & 58 & $45.47^{*}$ & 21.53 & 39.81 & 51.13 \\
\hline & 3 & 59 & $41.41^{*}$ & 18.58 & 36.56 & 46.25 \\
\hline \multirow[t]{3}{*}{ SSL3 } & 1 & 58 & 63.21 & 26.85 & 56.15 & 70.27 \\
\hline & 2 & 58 & $48.50^{*}$ & 22.90 & 42.48 & 54.52 \\
\hline & 3 & 59 & $47.22^{*}$ & 23.87 & 41.00 & 53.44 \\
\hline
\end{tabular}

${ }^{*} \mathrm{p}<0.05$ for stress levels of the intervention groups compared to the control

In the Repeated Measures ANOVA it was found that there were no significant differences in the second evaluation after 12 sessions ( $S S L 2)(F=21.92 / p=0.000)$, nor at the 30 day follow-up $(F=7.59 / 0=0.001)$. In Tukey's Post Hoc test it was observed that in the second evaluation (SSL2), the differences were between the Control group and Intervention groups $(p=0.000)$. In the third evaluation (SSL3), the differences were between the Control and the Protocol group $(p=0.004)$ and between the Control and the No protocol group $(p=0.002)$ (Figure 3$)$.

When evaluating the effect size from Cohen's d index, it was possible to observed that the No protocol group achieved the best result with $d$ of 1.15 (very large effect), with greatly reduced stress levels (36\%) for the SSL2. The Protocol group achieved an index of 0.79 
(large effect) in the SSL2, with an average reduction of stress levels (27\%). Both groups were able to maintain the positive results in the follow-up (Table 2 ).

Also an analysis of stress levels for sub-groups and for the presence or absence of previous morbidities was carried, to evaluate which conditions would respond better to the individualized auriculotherapy with no protocol.

In the analysis by stress levels, of the 175 subjects, 76 professionals presented stress above 60 points according to the SSL, corresponding to a high stress level and for the analysis of the evolution of the auriculotherapy treatment they were divided into 3 groups: Control (22) Protocol (25) and No protocol (29). A statistically significant difference was found in the ANOVA test for the SSL2 $(p=0.000)$ and SSL3 $(p=0.036)$. In the SSL2, using Tukey's Post Hoc test, it was found that the differences were between the Control and Protocol groups $(p=0.004)$ and the Control and No protocol groups $(p=0.000)$. In the SSL3, the Post $\mathrm{Hoc}$ test showed that the differences were only between the Control group and the No protocol group $(p=0.033)$. Percentage-wise, there was a reduction of stress levels in the SSL2 of $44 \%$ for the No protocol group and $37 \%$ for the Protocol group. In the SSL3 at follow-up the reduced stress levels were maintained, with a $37 \%$ reduction for the No protocol group and $29 \%$ for the Protocol group. Cohen's index showed that the No protocol group obtained the strongest effect, with $d$ of 1.95 for the SSL2, equivalent to "enormous effect" and in the follow-up, the d of 2.59, also corresponding to the same classification. Regarding the Protocol group, stress was reduced by $37 \%$, with an index of 1.36 in the SSL2.

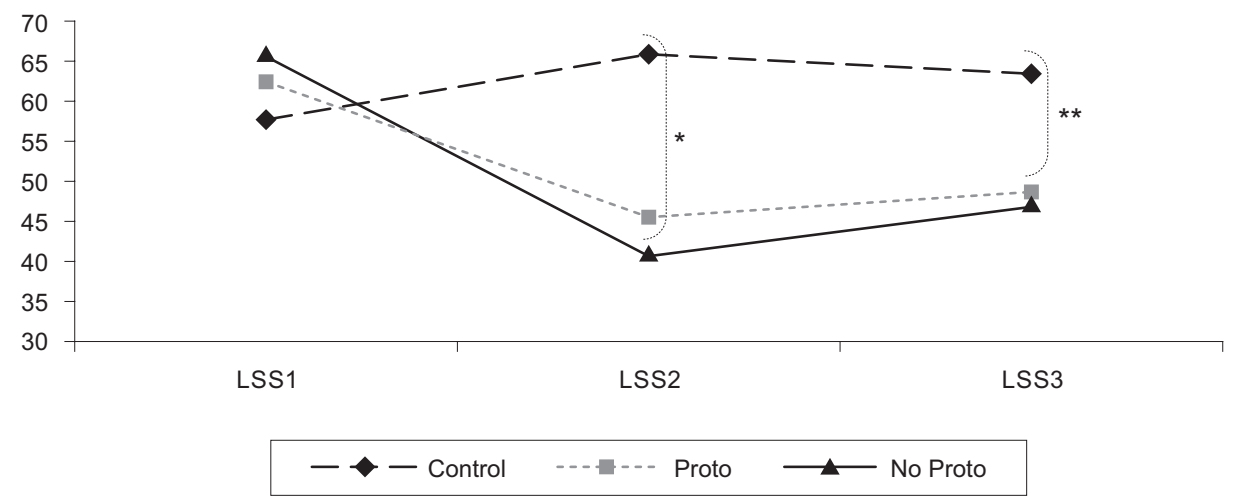

$* p=0.000$ between the means of the Intervention and Control groups

$* * p=0.004$ between the Protocol and Control groups and $p=0.002$ between the No protocol and Control groups

Figure 3 - Evolution of the stress levels according to the 3 groups. São Paulo, 2012

Table 2 - Effect sizes and percentage of change for the treatment at the 3 times, according to the 3 groups. São Paulo, SP, Brazil 2012

\begin{tabular}{ccccc}
\hline Group & Times & d & Dif. Dif. & 95\%Cl \\
\hline G1 & SSL1/SSL2 & 0.38 & 7.62 & $0.17 ; 15.01$ \\
G1 & SSL1/SSL3 & 0.24 & 5.46 & $2.91 ; 13.81$ \\
G2* & SSL1/SSL2 & 0.79 & -16.79 & $-24.71 ;-8.88$ \\
G2* & SSL1/SSL3 & 0.62 & -13.76 & $-21.93 ;-5.59$ \\
G3* & SSL1/SSL2 & 1.15 & -23.59 & $-31.14 ;-16.04$ \\
G3 $^{*}$ & SSL1/SSL3 & 0.77 & -17.78 & -27 \\
\hline
\end{tabular}

$* \mathrm{p}<0.05$ for the Intervention groups compared to the Control

In the analysis of the subjects with self-reported prior morbidities (52), the No protocol group (21) obtained better results than the Protocol group (17) in the SSL2. For this grouping a statistically significant difference was found in the SSL2 $(F=3.24 / p=0.048)$, according to the repeated measures ANOVA. In Tukey's test it was found that this difference was between the Control group and the No protocol group $(p=0.045)$. 
Percentage-wise the No protocol group achieved a large stress reduction (37\%) equivalent to Cohen's d index of 1.21 (very large effect).

The points most used in the No protocol group were the same points (Kidney, Brain Stem, Shen Men, Liver Yang 1 and 2) with the addition of points for local pain (Cervical, Lumbar), points to balance the meridians (Stomach, Spleen, Liver, Lung), and points with general systemic action, such as the Endocrine and Apex.

\section{Discussion}

The preliminary study that motivated the present study was conducted in a university hospital (UH), with 75 nurses randomized into three groups (Control without intervention, Needle group and Seed group). A protocol of 3 auricular points (Kidney, Brainstem and Shen Men) was used and it was found that there was a statistically significant difference in the intergroup analysis between the Control group and the Needle group. The Seed group did not achieve the same efficacy. Stress scores of 54.36 were found at the baseline for the Control group, 66.82 for the Needle group and 63.27 for the Seed group ${ }^{(5)}$. The stress levels observed in the present study were similar to these. At the baseline the stress scores were 57.76 for the Control group, 62.26 for the Protocol group, and 64.83 for the No protocol group.

In the UH study, with 44 subjects (58.7\%) with average levels of stress, no statistically significant difference was found post-treatment in the auriculotherapy with either needle or seed. However, 31 subjects $(41.3 \%)$ with high stress levels obtained a statistical difference after 8 sessions of auriculotherapy for the Needle group, reaching a $21 \%$ reduction and $d$ index of 1.13 (very large effect), with maintenance of the results at the 15 day follow up ${ }^{(5)}$. To compare the effect sizes between the two studies, only data from subjects with high levels of stress were used. The percentages of stress reduction in the present study were higher for the No protocol group (44\%) with maintenance of the reduction at the follow-up of $37 \%$. The effect size for the No protocol group was 1.95 (very large effect) and was even higher at the follow-up, with $d$ index of 2.59.

As there was a higher prevalence of people with comorbidities in the No protocol group, it was asked, among other things, whether only six weeks of treatment was sufficient to determine differences between the results of the two Intervention groups. To be able to comprehend the complexity of the issue, a survey was made of recent studies on auriculotherapy for the treatment of psychological conditions such as anxiety and stress and some references were found.

Auriculotherapy studies were conducted to evaluate preoperative anxiety reduction with just a single session. The Relaxation point group was compared to the Shen Men group and one Sham group(6). Another study evaluated the same relaxation point with acupressure, in a single session, to decrease anxiety and stress in patients with gastrointestinal problems in prehospital transportation ${ }^{(7)}$. Auricular acupuncture has also been used to control acute anxiety in dental extraction. A single session was performed comparing auriculotherapy with the intranasal medication midazolam, placebo acupuncture and a control group without treatment ${ }^{(8)}$.

Some trials were found for stress, in which the number of sessions ranged from seven to eight, with one per week. A clinical trial was performed to decrease anxiety and stress levels in university students using two auricular points (Shen Men and Brainstem), with one per week, for seven weeks, using mustard seeds(17). Another study demonstrated the efficacy of auriculotherapy in eight sessions with the same points as the previous protocol (Shen Men and Brainstem) using semi-permanent needle in 41 subjects belonging to the nursing staff of the Intensive Care Unit of a private hospital in São Paulo(9). A single-blind randomized clinical trial was conducted with 71 nursing students to evaluate the efficacy of auricular points (Brainstem and Shen Men) to reduce stress and anxiety. Eight sessions, one per week, with semi-permanent needles were performed $^{(10)}$.

According to the studies presented, the number of sessions may vary according to the proposal of the clinical trial, and in the present study 12 sessions of auriculotherapy over six weeks were proposed. It is not possible to affirm, however, whether the higher percentage of improvement in the No protocol group could achieve a statistical difference with the Protocol group, if the treatment time had been longer.

In the analysis by subgroup it was observed that the stress levels of people with prior self-reported morbidities were not reduced in the Protocol group, with this achieved only in the No protocol group. The Protocol group could not cover another condition that was not stress or some disharmonies associated with some points of the protocol, being very effective especially in healthy people. Regarding the follow-up at 30 days, in the analysis of the positive residual effect of auriculotherapy, the subjects who did not have chronic morbidities were those who were best able to maintain 
this improvement. Patients presenting morbidities could not sustain the improvement in the post-treatment.

Related to this, there is no consensus in the literature about how many sessions would be required to obtain the best result from therapies such as acupuncture and auriculotherapy in relation to chronic diseases ${ }^{(18)}$. Auriculotherapy may be a supporting technique for the treatment of chronic diseases and treatments considered to be of longer duration, such as four to six weeks ${ }^{(19)}$. In this sense, it is suggested that longitudinal studies be conducted in the future, with treatment and followup of longer duration, so that the more lasting residual effects of individualized auriculotherapy can be carefully evaluated, especially in stressed subjects that present some prior morbidity.

Other therapies have been used for the control of stress, such as cognitive behavioral therapy, meditation programs, guidance for changing lifestyle, such as smoking cessation, attention to nutrition, physical exercise and blood pressure control. Coping with stress may involve a variety of techniques and procedures the purpose of which would be to help workers to deal better with their symptoms. Guidance on relaxation, such as biofeedback, progressive muscle relaxation, and cognitive-behavioral skills training(20) are recommended.

The meditation practices for stress reduction have been researched in depth and a meta-analysis of the clinical trials has been carried out which covered a broad spectrum of subjects with comorbidities (cancer, cardiopathy, depression, anxiety, etc.) and stress. The proposed intervention was a collective meditation program that sought to alleviate the suffering associated with physical, psychosomatic and psychiatric disorders. The technique achieved an effect size for the reduction of physical symptoms of $d=0.42$ in 566 subjects in nine different studies $(p<0.0001)$. An effect size of $d=0.50$ was also found for 18 studies with 894 subjects $(p<0.0001)$ regarding psychological symptoms ${ }^{(21)}$.

Another study was conducted to evaluate the efficacy and acceptability of acupuncture to treat Post Traumatic Stress disorder. The subjects were divided into three randomized groups (Acupuncture, Cognitive behavioral therapy and Control/waiting list). Both Intervention groups achieved statistical differences between the pre- and post-treatment, with the Acupuncture group achieving an effect size of $d=1.29$, similar to the Cognitive-behavioral therapy group $(\mathrm{d}=1.42)$. The reduction in symptoms was maintained at the follow-up of 3 months for both interventions ${ }^{(22)}$.
In terms of effect size and percentage of improvement, the result obtained by the Auriculotherapy group was similar or even better in relation to decreasing stress levels compared to other techniques. The opportunity to encounter some of the benefits of the technique for minimizing stress symptoms and improve well-being was provided to those who agreed to participate in the trial. Interventions such as auriculotherapy, which has the potential to be easily learned by nurses and healthcare professionals, are interesting proposals as they reduce costs and provide effective health promotion alternatives. Further studies aimed at the economic evaluation of cost-effectiveness and cost-benefit are essential so that auriculotherapy may become more widespread, recognized and included in the various healthcare sectors, since there is already legislation that regulates the use of multi-professional acupuncture by the Brazilian National Health System (SUS) $)^{(23)}$.

\section{Conclusions}

The answers found in this study demonstrated that auriculotherapy with and without a protocol was effective in reducing levels of stress according to Vasconcelos' Stress Symptoms List. Better results were found in the No protocol group compared to the Protocol group, regarding the effect size and the percentage of change, demonstrating that individualized auriculotherapy expands the scope of the technique, especially among those who presented higher stress and prior morbidities. The protocol of auricular points proposed for reducing stress levels was effective and the Kidney, Shen Men, Brainstem points in toning and the Liver Yang 1 and 2 in sedation were sufficient to produce positive results in 12 sessions.

\section{References}

1. Gatti MFZ, Leão ER, Silva MJP, Puggina ACG. Comparison between anxiety and stress levels displayed by and perceived by the nursing collective. Enferm Global.2004;5:1-12. [acesso 8 fev 2011]. Disponível em: http://revistas.um.es/eglobal/article/view/540

2. Silva JLL, Melo ECP. Estresse e implicações para o trabalhador de Enfermagem. Informe-se em Promoção da Saúde. 2006;2(2):16-8.

3. Fugulin FMT, Gaidzinski RR, Kurcgant P. Expected and unexpected absences of the nursing team at the inpatient units of a university hospital at the University of São Paulo-Brazil. Rev Esc Enferm USP. 2003;37(4):109-17. 
4. Coelho NM Neto, Garbaccio JL. O estresse ocupacional no serviço de Enfermagem hospitalar: reconhecimento e minimização. Interseção. 2008;1(2):71-81.

5. Kurebayashi LFS, Gnatta JR, Borges TP, Belisse G, Coca, S, Minami A, et al. The applicability of auriculotherapy with needles or seeds to reduce stress in nursing professionals. Rev Esc Enferm USP. 2012;46(1):89-95.

6. Wang SM, Peloquim C, Kain ZN. The Use of Auricular Acupuncture to Reduce Preoperative Anxiety. Anesthesia \& Analgesia.2001;93:1178-80.

7. Kober A, Scheck T, Schubert B, Strasser H, Gustorff B, Bertalanffy $P$, et al Auricular acupressure as a treatment for anxiety in prehospital transport settings. Am Soc Anesthesiol. 2003;98(6):1328-32.

8. Karst $M$, Winterhalter $M$, Münte $S$, Francki $B$, Hondronikos A, Eckardt $A$, et al. Auricular acupuncture for dental anxiety: a randomized controlled trial. Anesth Analg. 2007;104(2):295-300.

9. Giaponesi ANL, Leão ER. A auriculoterapia como intervenção para redução do estresse da equipe de Enfermagem em terapia intensiva. Nursing. (São Paulo) 2009;12(139):575-9.

10. Do Prado JM, Kurebayashi LFS, Silva MJP. Efficacy of auriculotherapy for the reduction of stress in nursing studentes: a randomized clinical trial. Rev. Latino-Am. Enfermagem. 2012;20(4):727-35.

11. MacPherson $H$, Altaman DG, Hammerschlag $R$, Li YP, Wu TX, White A, et al. Revised Standards for Reporting Interventions in Clinical Trials of Acupuncture (STRICTA): Extending the CONSORT Statement. Aust J Acupunct Chin Med 2010;5(2):8-22.

12. Richardson J. The use of randomized control trials in complementary therapies: exploring the issues. J Adv Nurs. 2000;32(2):398-406.

13. Nguyen CR. Nada de cume, sem raiz: acupuntura do ano 2000. Rev Paul Acupuntura.1997;3(2):55-6.

14. Conselho Federal de Enfermagem (COFEN) (BR). Resolução COFEN 328/2008. Regulamenta no Sistema COFEN/Conselhos Regionais a atividade de acupuntura e dispões sobre o registro da especialidade [Internet]. Brasília; 2008. [acesso 29 jan 2011]. Disponível em: http://site.portalcofen.gov.br/node/5414

15. Ferreira EAG, Vasconcellos EG, Marques AP. Assessment of pain and stress in fibromyalgia patients. Rev Bras Reumatol. 2002;42:104-10.

16. Landgren K. Explanatory models for acupuncture. Ear Acupuncture: a practical guide. New York: Elsevier; 2008. p. 37-53.

17. Nakai LS, Lyra CS, Marques AP. Eficácia da auriculoterapia na diminuição dos níveis de estresse e ansiedade de adultos saudáveis. [acesso 28 set 2013]. Disponível em: https://uspdigital.usp.br/siicusp/cdOnlin eTrabalhoVisualizarResumo?numeroInscricaoTrabalho= $1763 \&$ numeroEdicao $=16$

18. Lao L, Ezzo J, Berman BM, Hammerschlag R. Avaliação da eficácia Clínica da Acupuntura: considerações para o desenho de futuras pesquisas em acupuntura. In: Stux G, Berman B, Pomeranz B. Basics of Acupuncture. 5ed. Berlin: Springer; 2005. p. 207-32.

19. Diaz Ontivero CM. Papel de la Auriculoterapia en el manejo de las enfermedades crónicas no transmisibles en la comunidad. Cuba; 2006 [acesso 20 ago 2013]. Disponível em: http://www.monografias.com/trabajos41/ auriculoterapia/auriculoterapia.shtml.

20. Hurrell JJ Jr, Sauter SL. Stress Ocupacional: causas, consequências, prevenção e intervenção. In: Rossi $A M$, Perrewé PL, Meurs JA. Stress e Qualidade de Vida no Trabalho. São Paulo: Atlas; 2011. p. 213-30.

21. Grossman P, Niemann L, Schimdt S, Walach $H$. Mindfulness-based stress reduction and health benefits: a Meta-analysis. J Psychosom Res. [Internet]. 2004 [acesso 17 fev 2013].;57:35-43. Disponível em: http://www. openground.com.au/articles/MBSR_MA_JPR_2004.pdf

22. Hollifield M, Sinclair-Lian N, WarnerT, Hammerschlag

R. Acupuncture for Posttraumatic Stress Disorder: a Randomized Controlled Pilot Trial. J Nerv Ment Dis.2007;195(6):504-13.

23. Ministério da Saúde (BR). Portaria n. 971/2006. Aprova a Política Nacional de Práticas Integrativas e Complementares (PNPIC) no Sistema Único de Saúde. Diário Oficial da União, Brasília, 4 maio 2006. Seção 1, p. 20-5.
Received: Apr. 15 2013

Accepted: Dec. $12^{\text {th }} 2013$ 